\title{
Effect of short term treatment of non-gonococcal urethritis with minocycline
}

\author{
D TAYLOR-ROBINSON,* R T EVANS,* E D COUFALIK,* AND J K OATES $\dagger$ \\ From the *Division of Sexually Transmitted Diseases, MRC Clinical Research Centre, Harrow, Middlesex, and \\ the $†$ Department of Genitourinary Medicine, Westminster Hospital, London
}

SUMMARY Two hundred and forty four men with non-gonococcal urethritis (NGU) took part in a trial of minocycline. Chlamydiae were isolated from $34 \%$, ureaplasmas from $47 \cdot 1 \%$, and Mycoplasma hominis from $10 \cdot 2 \%$. These micro-organisms were isolated least often from men suffering their third or more attack of NGU, and men in this group failed most often to respond to minocycline. Irrespective of the micro-organisms isolated originally or the number of previous attacks, the failure rate $(10 \%)$ for men receiving minocycline for 10 days was significantly less than for those receiving this antibiotic for one or two days. More than half of the men suffering third attacks from whom micro-organisms were not isolated failed to respond to these short regimens. One of the lowest failure rates (4\%) after short term treatment, however, was seen in men experiencing first attacks who yielded only ureaplasmas with or without $M$ hominis, which indicates the importance of ureaplasmas in this group of patients. Chlamydiae were not reisolated from any patient after treatment, irrespective of its duration, and the only ureaplasmas that were reisolated were from nine patients who carried tetracycline resistant strains. Reasons for the absence of chlamydiae and ureaplasmas in the presence of disease and the need to look for other microorganisms as a cause of NGU are discussed among other issues raised by these results.

\section{Introduction}

Many studies have attempted to establish the cause of non-gonococcal urethritis (NGU). ${ }^{1}$ Genital strains of Chlamydia trachomatis organisms (chlamydiae) are generally accepted as causing up to $50 \%$ of cases of NGU, ${ }^{2}$ and Ureaplasma urealyticum organisms (ureaplasmas) may cause a smaller, ill defined, proportion of cases, ${ }^{3}$ though the carriage of ureaplasmas in some healthy men has always created a difficulty in assessing the role of these organisms in disease. Neither chlamydiae nor ureaplasmas are isolated from some patients, and other tetracycline sensitive organisms are probably implicated, particularly as some of the patients who are free from chlamydiae and ureaplasmas respond to tetracycline treatment. ${ }^{4}$ Indeed, the most widely prescribed antibiotics for treating NGU are the tetracyclines, to which chlamydiae and (usually) ureaplasmas are sensitive. In a previous study we showed that a seven

Address for reprints: Dr D Taylor-Robinson, Division of Sexually Transmitted Diseases, MRC Clinical Research Centre, Watford Road, Harrow, Middlesex HA1 3UJ

Accepted for publication 9 May 1985 day course of the semisynthetic tetracycline, minocycline, was more effective than a placebo in controlling the disease and that chlamydia negative, ureaplasma positive patients were clinically more responsive to the antibiotic than to the placebo, which suggested a role for the ureaplasmas. ${ }^{4}$ Even longer treatment has been advocated, ${ }^{5}$ but the effect of shorter treatment with tetracyclines has been studied rarely.$^{67}$ In the study reported here we compare one, two, and 10 day minocycline treatment regimens, assessing the effects both clinically and microbiologically. The results indicate that brief treatment leads to the disappearance of the microorganisms, but they vindicate longer treatment for clinical cure. Furthermore, we discuss the relation between ureaplasmas and NGU provided by the results of this study.

\section{Patients and methods}

\section{PATIENTS}

We examined consecutive patients with urethral discharge who presented at each of two clinics (A and B). Urethral smears were taken with a bacteriological loop and stained with Gram reagent. If $\mathbf{1 5}$ or more 
polymorphonuclear leucocytes (PMNL) were seen in one microscope field (800-1000 x), Gram negative diplococci and yeasts were not seen, and the patient had not received antibiotic treatment within the previous month, he was admitted to the trial. We included 150 patients from each clinic in the trial originally, that is 50 within each treatment group, but some were excluded eventually on the basis of the criteria mentioned below.

\section{MINOCYCLINE TREATMENT REGIMENS}

The antibiotic (Minocin: Lederle, Gosport, England) was given orally during three different periods as follows: (1) a $200 \mathrm{mg}$ loading dose followed by $100 \mathrm{mg}$ every 12 hours for 10 days; (2) a $200 \mathrm{mg}$ loading dose followed by $100 \mathrm{mg}$ every 12 hours for two days and then placebo every 12 hours until 10 days had elapsed, or (3) a $300 \mathrm{mg}$ loading dose followed by placebo every 12 hours until 10 days had elapsed.

The tablets were provided in identical strips, identifiable only by the patient's number. The randomisation code was not made available to clinicians or microbiologists until all microbiological procedures had been completed.

\section{EXPERIMENTAL DESIGN}

The study was approved by the ethical committees of the two clinics, and the patients were informed fully of the nature of the study. Specimens were collected initially and one, two, and three weeks later; on each occasion the patients were examined clinically. If a patient had had sexual intercourse during the course of the trial or cultural examination of specimens showed gonococci or yeasts, the results for that patient were not included in the assessment. Treatment was considered to have failed if patients did not respond clinically and cytologically ( $<5$ PMNL per high power field) to a minocycline regimen or if they responded but relapsed, apparently spontaneously, within the 21 day period of the trial. If the patient was not cured or relapsed, as indicated by symptoms and finding $\geqslant 5$ PMNL per high power field in a urethral smear, he was treated either with a full 10 day course of minocycline or with erythromycin.
COLLECTION OF SPECIMENS AND ISOLATION OF MICRO-ORGANISMS

Specimens were collected for the isolation of chlamydiae, ureaplasmas, and Mycoplasma hominis. A cotton wool tipped endourethral swab was inserted about $2 \mathrm{~cm}$ into the urethral canal and expressed in 1.8 $\mathrm{ml}$ of mycoplasma liquid transport medium. After a maximum of three hours samples were stored at $-70^{\circ} \mathrm{C}$ until they were tested. They were titrated in medium containing urea for the detection of ureaplasmas and in medium containing arginine for $\boldsymbol{M}$ hominis. ${ }^{8}$ The presence of these micro-organisms was confirmed by subculture in liquid media, and $M$ hominis was identified by the use of specific antiserum in the disc test of growth inhibition. A specimen for chlamydial culture was always taken second by passing a similar swab 3-4 cm into the urethra. It was expressed in sucrose-phosphate transport medium and stored immediately in liquid nitrogen until inoculated into McCoy cell cultures. In all cases, the cells were treated with 4500 rad $\gamma$ irradiation from a cobalt 60 source three days before inoculation. They were stained with Giemsa reagent and examined for inclusions.

\section{ANTIBIOTIC SENSITIVITY TESTS}

We tested the sensitivity of ureaplasmas to minocycline and erythromycin as described previously. 9

\section{STATISTICAL ANALYSIS}

We applied $\chi^{2}$ analysis or multiple regression in the logit scale analysis to the data. The results were considered to be significant if $p \leqslant 0 \cdot 05$.

\section{Results}

ISOLATION RATES FOR VARIOUS MICRO-ORGANISMS We included in the trial 113 men who attended clinic $A$ and 131 who attended clinic B. Table I shows the occurrence of chlamydiae, ureaplasmas, and $M$ hominis in these patients at their first visit. Chlamydiae were isolated from $40 \%$ of patients in clinic A and from $29 \%$ of patients in clinic B, an overall rate of $34 \%$. Ureaplasmas were isolated from

TABLE I Isolation of micro-organisms from men with non-gonococcal urethritis experiencing first and subsequent attacks

\begin{tabular}{|c|c|c|c|c|c|}
\hline \multirow[b]{2}{*}{ Microbiological status originally } & \multicolumn{5}{|c|}{ No $(\%)$ of patients of indicated microbiological status: } \\
\hline & $\begin{array}{l}\text { At clinic } A \\
(n=113)\end{array}$ & $\begin{array}{l}\text { At clinic } B \\
(n=131)\end{array}$ & $\begin{array}{l}\text { Experiencing } \\
\text { first attack* } \\
(n=96)\end{array}$ & $\begin{array}{l}\text { Experiencing } \\
\text { second attack } \\
(n=73)\end{array}$ & $\begin{array}{l}\text { Experiencing third } \\
\text { or more attack* } \\
(n=75)\end{array}$ \\
\hline $\begin{array}{l}\text { Chlamydia positive } \\
\text { Ureaplasma positive } \\
\text { Mycoplasma hominis positive } \\
\text { None of above isolated. }\end{array}$ & $\begin{array}{l}45(39 \cdot 8) \\
51(45 \cdot 1) \\
12(10 \cdot 6) \\
38(33 \cdot 6)\end{array}$ & $\begin{array}{l}38(29) \\
64(48 \cdot 9) \\
13(9 \cdot 9) \\
43(32 \cdot 8)\end{array}$ & $\begin{array}{l}38(39 \cdot 6) \\
54(56 \cdot 3) \\
14(14 \cdot 6) \\
23(24)\end{array}$ & $\begin{array}{l}29(39 \cdot 7) \\
33(45 \cdot 2) \\
6(8 \cdot 2) \\
24(32 \cdot 9)\end{array}$ & $\begin{array}{r}16(21 \cdot 3) \\
29(38 \cdot 7) \\
4(5 \cdot 3) \\
34(45 \cdot 3)\end{array}$ \\
\hline
\end{tabular}


$45 \%$ and $49 \%$ of patients attending clinic A and B, respectively, an overall rate of $47 \cdot 1 \%$. M hominis was isolated from $11 \%$ of patients in clinic $A$ and from $10 \%$ of those in clinic $B$, an overall rate of $10.2 \%$. These various micro-organisms were not isolated from $34 \%$ and $33 \%$ of patients in clinic $A$ and $B$, respectively, an overall rate of $33 \cdot 2 \%$. The isolation rates for patients in the two clinics were compared statistically, and as there was no significant difference the data for both clinics were combined for further analysis.

MICRO-ORGANISMS ISOLATED IN RELATION TO PREVIOUS ATTACKS OF NGU

The isolation of micro-organisms from men who were experiencing their first attack of NGU was not significantly different from the isolation from men who were having a second attack $(\mathrm{p}>0.05)($ table I). However, when the recovery of micro-organisms from these two groups of patients was compared with that from patients suffering their third, or more, attack there was a significant difference $(\mathrm{p}<0.01)$, with fewer chlamydiae, ureaplasmas, and $M$ hominis isolated from the latter group, and consequently a greater rate of failing to isolate these micro-organisms.

\section{CLINICAL RESPONSE TO TREATMENT}

Table II shows that of 162 men from whom chlamydiae, ureaplasmas, $M$ hominis, or any combination of these micro-organisms were isolated originally, $28(17 \cdot 3 \%)$ failed to respond to any of the treatment schedules. In contrast, however, of 81 men from whom none of these micro-organisms was isolated originally, $25(30.9 \%)$ failed to respond. In other words, the failure rate was almost double in men not initially yielding these three micro-organisms, a difference that was significant $(p<0.025)$.

The failure rates for men experiencing first attacks
$(16 / 96 ; 16 \cdot 7 \%)$ or second attacks of NGU $(12 / 73$; $16 \cdot 4 \%$ ) were not different. Patients who were suffering at least their third attack, however, had double the failure rate $(25 / 75 ; 33 \%)$ of those in the other two categories, a difference that was significant $(p=0.005)$.

Irrespective of the micro-organisms isolated originally or the number of previous attacks of NGU, the failure rate for men receiving treatment for one day (20/76: 26\%) was not different from that for men given treatment for two days (25/89: $28 \%$ ). The failure rate for patients who received treatment for 10 days (8/79: 10\%), however, was significantly less $(\mathrm{p}<0.05)$.

Of patients receiving treatment for one or two days, the greatest failure rate $(12 / 22: 54 \cdot 5 \%)$ was seen among those from whom neither chlamydiae, ureaplasmas, nor $M$ hominis were isolated and who were experiencing at least their third attack. One of the lowest failure rates $(1 / 24: 4 \%)$ for short treatment was among men suffering first attacks and from whom only ureaplasmas, or ureaplasmas and $M$ hominis, had been isolated. Of patients receiving treatment for 10 days, none of 17 from whom only chlamydiae were isolated originally failed treatment, whereas five $(21 \%)$ of 24 from whom only ureaplasmas, or ureaplasmas and $M$ hominis, were isolated failed treatment: the five failures were not $M$ hominis positive. Overall, however, irrespective of the presence of $M$ hominis, the failure rate for patients given one, two, or 10 days treatment from whom only ureaplasmas were isolated $(14 / 79 ; 18 \%)$ was similar to that for patients from whom only chlamydiae were isolated $(7 / 46 ; 15 \%)$.

MICROBIOLOGICAL RESPONSE TO TREATMENT

Irrespective of the duration of minocycline treatment, or whether or not there had been a clinical response to

TABLE II Microbiological status originally and response to minocycline in relation to episode of non-gonococcal urethritis (NGU) and duration of treatment

\begin{tabular}{|c|c|c|c|c|c|c|c|c|c|}
\hline \multirow{2}{*}{$\begin{array}{l}\text { Episode } \\
\text { of } N G U\end{array}$} & \multirow{2}{*}{$\begin{array}{l}\text { Treatment } \\
\text { period } \\
\text { (days) }\end{array}$} & \multicolumn{8}{|c|}{ No of patients with indicated micro-organisms (No who failed treatment or relapsed): } \\
\hline & & $C+$ & $C+U+$ & $C+U+H+$ & $\mathrm{C}+\mathrm{H}+$ & $U+$ & $U+H+$ & $H+$ & $\mathrm{C}-\mathrm{H}-\mathrm{U}-$ \\
\hline First & $\begin{array}{r}1 \\
2 \\
10\end{array}$ & $\begin{array}{l}5(2) \\
4(1) \\
7(0)\end{array}$ & $\begin{array}{l}6(3) \\
9(0) \\
3(1)\end{array}$ & $\begin{array}{l}1(0) \\
0(0) \\
1(0)\end{array}$ & $\begin{array}{l}2(1) \\
0(0) \\
0(0)\end{array}$ & $\begin{array}{l}9(1) \\
7(0) \\
8(0)\end{array}$ & $\begin{array}{l}5(0) \\
3(0) \\
2(0)\end{array}$ & $\begin{array}{l}0(0) \\
1(0) \\
0(0)\end{array}$ & $\begin{array}{l}9(2) \\
8(5) \\
6(0)\end{array}$ \\
\hline Second & $\begin{array}{r}1 \\
2 \\
10\end{array}$ & $\begin{array}{l}5(0) \\
5(0) \\
4(0)\end{array}$ & $\begin{array}{l}4(0) \\
5(2) \\
3(0)\end{array}$ & $\begin{array}{l}0(0) \\
1(1) \\
0(0)\end{array}$ & $\begin{array}{l}0(0) \\
2(1) \\
0(0)\end{array}$ & $\begin{array}{l}5(0) \\
4(1) \\
8(2)\end{array}$ & $\begin{array}{l}0(0) \\
2(1) \\
1(0)\end{array}$ & $\begin{array}{l}0(0) \\
0(0) \\
0(0)\end{array}$ & $\begin{array}{r}5(2) \\
7(2) \\
12(0)\end{array}$ \\
\hline $\begin{array}{l}\text { Third } \\
\text { or more }\end{array}$ & $\begin{array}{r}1 \\
2 \\
10\end{array}$ & $\begin{array}{l}4(2) \\
2(0) \\
6(0)\end{array}$ & $\begin{array}{l}2(0) \\
1(0) \\
1(0)\end{array}$ & $\begin{array}{l}0(0) \\
0(0) \\
0(0)\end{array}$ & $\begin{array}{l}0(0) \\
0(0) \\
0(0)\end{array}$ & $\begin{array}{r}5(2) \\
11(4) \\
5(3)\end{array}$ & $\begin{array}{l}2(0) \\
2(0) \\
0(0)\end{array}$ & $\begin{array}{l}0(0) \\
0(0) \\
0(0)\end{array}$ & $\begin{array}{r}7(5) \\
15(7) \\
12(2)\end{array}$ \\
\hline Total & & $42(5)$ & $34(6)$ & $3(1)$ & $4(2)$ & $62(13)$ & $17(1)$ & $1(0)$ & $81(25)$ \\
\hline
\end{tabular}

$\mathrm{C}=$ Chlamydia trachomatis; $\mathrm{U}=$ Ureaplasma urealyticum; $\mathbf{H}=$ Mycoplasma hominis; $+=$ isolated; $-=$ not isolated. 
treatment, chlamydiae were not isolated from any patient at follow up visits to the clinics. This microbiological response was seen also for $M$ hominis and ureaplasmas, except in the case of nine patients from whom tetracycline resistant ureaplasma strains were recovered. The minimum inhibitory concentration of minocycline ranged from 0.3 to 40 $\mathrm{mg} / \mathrm{l}$. All of the strains were sensitive, however, to $0.08 \mathrm{mg} / \mathrm{l}$ erythromycin. Only one of the tetracycline resistant strains was isolated from a patient with persistent urethritis.

\section{Discussion}

The overall isolation rates for chlamydiae, ureaplasmas, and $M$ hominis in this study are in keeping with those of other studies that we have conducted on patients with NGU. ${ }^{40-12}$ Mhominis was isolated rarely and, apart from one occasion, always in conjunction with the two other micro-organisms. For these reasons it is difficult to make comments about its role in disease. Against this background, however, several points are of interest, particularly in relation to chlamydiae and ureaplasmas. First, these microorganisms, and $M$ hominis too, were isolated most often from patients who were allegedly experiencing their first attack of NGU. The failure to recover them as often in subsequent attacks could mean that different micro-organisms are responsible or that chlamydiae and ureaplasmas, though initiating these episodes, disappear more rapidly than they do in the first attack ("immune clearance") and fail to be detected. Both explanations seem plausible but the latter does not, of course, account for the failure to recover chlamydiae, ureaplasmas, or $M$ hominis from at least a quarter of patients suffering a first attack of NGU. Could this "no micro-organism" gap in reality be filled by chlamydiae or ureaplasmas? It is possible that some alleged first attacks of NGU are in fact second or even subsequent episodes accounted for by these micro-organisms, which have been removed rapidly by "immune clearance". It seems unlikely, however, that this is the full explanation. It might also be argued that chlamydial and ureaplasmal isolation techniques of greater sensitivity could narrow the "no micro-organism" gap. This seems to be unlikely, however, as use of the monoclonal antibody technique for detecting chlamydiae directly in smears ${ }^{13}$ indicates that for these organisms, at least, currently available culture techniques are sufficiently sensitive to detect all viable organisms in the urethra. Of course, not all ureaplasmas appear to be pathogenic and it is, indeed, an assumption that chlamydiae recovered from patients with NGU are in every case responsible for the disease. Even without this caveat, however, it seems that there are sufficient reasons for looking for other micro-organisms as a cause of NGU. Whether
Bacteroides ureolyticus ${ }^{14}$ or Mgenitalium $^{15}$ turn out to be substantial causes remains to be seen.

The second point of interest is that failure to respond clinically to short or long term treatment was seen most often in men who were experiencing their third or more attack of NGU, somewhat in keeping with the experience of Munday et al. ${ }^{11}$ Furthermore, although 10 day treatment was effective almost irrespective of the initial microbiological status, as noted by Munday et al, ${ }^{11}$ short term treatment failed most often in those from whom micro-organisms were not isolated, an observation similar to that of Bowie et al using longer treatment. ${ }^{16}$ It could be argued that if repeated attacks, particularly those in which there is failure to isolate chlamydiae and ureaplasmas, are to some extent immunologically mediated, then antibiotic treatment would not be expected to have the same affect as in a primary attack. Alternatively, if other micro-organisms are responsible they may not be cleared as easily as chlamydiae and ureaplasmas. Indeed, the third point of interest concerns the disappearance of these micro-organisms. Tetracycline resistant ureaplasmas excepted, there has been a notable failure to recover either chlamydiae or ureaplasmas after six to seven days of tetracycline treatment. ${ }^{41116}$ In this study, apart from a few tetracycline resistant ureaplasmas, none of the microorganisms was recovered even after only one to two days of treatment. Despite their disappearance, however, disease continued or recurred in some patients. In agreement with some other workers, ${ }^{11} 12$ this does not seem to have been associated with resistant ureaplasmas as reported by Stimson et al. ${ }^{17}$ One explanation for the discrepancy between the absence of organisms and the presence of disease would be the existence of other causative microorganisms that are eliminated only by a 10 day course of treatment. On the other hand, chlamydiae and ureaplasmas may only appear to have been eliminated by a short course of treatment and may, in fact, still be present and capable of causing disease. This seems feasible in the case of chlamydiae where a short course of minocycline may be insufficient to kill all intracellular organisms. Ureaplasmas, however, unless taken up by inflammatory cells, remain extracellular and are therefore more likely to be affected by short course treatment. Indeed, the best response to one or two days of minocycline treatment was seen in patients who possessed only ureaplasmas, with or without $M$ hominis, and who ostensibly were experiencing their first attack of NGU: only one of 24 failed to respond, perhaps a further indication of the aetiological role of ureaplasmas in this group of patients.

These reflections on short course treatment raise two possibilities. The first is that it may be feasible to detect by rapid methods patients who are suffering 
first attacks and are infected only by ureaplasmas and to treat them successfully with a short course of tetracycline. The second is that short term tetracycline treatment of patients with gonorrhoea (when chlamydiae often exist only in small numbers if at all) may prevent post gonococcal urethritis as effectively as a longer course of treatment. The validity or otherwise of these suggestions needs testing under appropriate clinical trial conditions.

We thank Lederle Laboratories for supplying the Minocin.

\section{References}

1. Bowie WR. Urethritis in males. In: Holmes KK, Mårdh P-A, Sparling PF, Wiesner PJ, eds. Sexually transmitted diseases. New York: McGraw-Hill, 1984:638-50.

2. Taylor-Robinson D, Thomas BJ. The role of Chlamydia trachomatis in genital-tract and associated diseases. $J$ Clin Pathol 1980;33:205-33.

3. Taylor-Robinson D. Mycoplasma infections of the human urogenital tract with particular reference to non-gonococcal urethritis. Ann Microbiol (Paris) 1984;135A:129-34.

4. Prentice MJ, Taylor-Robinson D, Csonka GW. Non-specific urethritis. A placebo-controlled trial of minocycline in conjunction with laboratory investigations. British Joural of Venereal Diseases 1976;52:269-75.

5. John J. Efficacy of prolonged regimes of oxytetracycline in the treatment of nongonococcal urethritis. British Journal of Venereal Diseases 1971; 47:266-8.

6. Holmes KK, Johnson DW, Floyd TM. Studies of venereal disease. III. Double-blind comparison of tetracycline hydrochloride and placebo in treatment of nongonococcal urethritis. JAMA 1967;202:474-6.
7. Grimble AS, Amarasuriya KL. Non-specific urethritis and the tetracyclines. British Journal of Venereal Diseases 1975;51:198205.

8. Taylor-Roinson D, Furr PM. Recovery and identification of human genital tract mycoplasmas. Isr J Med Sci 1981;17:64853.

9. Taylor-Robinson D, Furr PM. The static effect of rosaramicin on Ureaplasma urealyticum and the development of antibiotic resistance, J Antimicrob Chemother 1982;10:185-91.

10. Coufalik ED, Taylor-Robinson D, Csonka GW. Treatment of nongonococcal urethritis with rifampicin as a means of defining the role of Ureaplasma urealyticum. British Journal of Venereal Diseases 1979:55:36-43.

11. Munday PE, Altman DG, Johnson AP, Thomas BJ, TaylorRobinson D. Persistent and recurrent non-gonococcal urethritis without evidence of current infection. European Journal of Sexually Transmitted Diseases 1982;1:15-20.

12. Hawkins DA, Taylor-Robinson D, Evans RT, Furr PM, Harris JRW. Unsuccessful treatment of non-gonococcal urethritis with rosoxacin provicies information on the aetiology of the disease. Genitourin Med 1985;61:51-5.

13. Thomas BJ, Evans RT, Hawkins DA, Taylor-Robinson D. Sensitivity of detecting Chlamydia trachomatis elementar bodies in smears by use of a fluorescein-labelled monoclonal antibody: comparison with conventional chlamydial isolation. J Clin Patholl $984 ;$ 37:812-6.

14. Fontaine EA, Taylor-Robinson D, Hanna NF, Coufalik ED Anaerobes in men with urethritis. British Journal of Venereal Diseases 1982;58:321-6.

15. Taylor-Robinson D, Furr PM, Hanna NF. Microbiological and serological study of non-gonococcal urethritis with special reference to Mycoplasma genitalium. Genitourin Med 1985;61:319-24.

16. Bowie WR, Alexander ER, Stimson JB, Floyd JF, Holmes KK. Therapy for nongonococcal urethritis. Double-blind randomized comparison of two doses and two durations of minocycline. Ann Intern Med 1981;95:306-11.

17. Stimson JB, Hale J, Bowie WR, Holmes KK. Tetracyclineresistant Ureaplasma urealyticum: a cause of persistent nongonococcal urethritis. Ann Intern Med 1981;94:192-4. 